\title{
Population genetic structure of and inbreeding in an insular cattle breed, the Jersey, and its implications for genetic resource management
}

\author{
L Chikhi $^{1,2,5}$, B Goossens ${ }^{3,5}$, A Treanor ${ }^{4}$ and MW Bruford ${ }^{1,3}$ \\ ${ }^{1}$ Institute of Zoology, Regent's Park, London NW1 4RY, UK; ${ }^{2}$ Department of Biology, University College London, Darwin Building, \\ London WC1E 6BT, UK; ${ }^{3}$ School of Biosciences, Cardiff University, PO Box 915, Cathays Park, Cardiff CF10 3TL, UK; ${ }^{4}$ Ministry of \\ Agriculture, States of Jersey, UK
}

The Jersey is a ubiquitous and successful breed of cattle that originates from the UK Channel Island of Jersey. While the breed has been exported extensively, no imports have taken place to the island since 1789 , leading to a concern regarding possible losses of genetic diversity and increased inbreeding. We have conducted the first large-scale genetic analysis of the Jersey cattle using only samples from the island. A total of 223 cattle from all parishes except one were genotyped for 12 microsatellite loci. The average number of alleles per locus and expected heterozygosity were found to be comparatively high $\left(n_{\mathrm{A}}=4, H_{\mathrm{e}}=0.64\right)$ with respect to that observed in a number of continental breeds. Only breeds that have been upgraded and are therefore the result of admixture are clearly more variable than the Jersey. We also found a significant but limited amount of genetic differentiation between parishes $\left(F_{s t}=0.013\right)$, or even between farms
$\left(F_{s t}=0.035\right)$ despite an apparent lack of movement. This is confirmed by the application of two recent statistical methods. A Bayesian partition analysis shows that the most probable value of $K$, the number of possible hidden partitions, is $1(P \sim 0.98) . K=2$ has a much lower probability $(P \sim 0.02)$ while other values are essentially zero. Similarly, we were able to show that there was no support for departure from panmixia other than due to population structure, and thus that there is sufficient background gene flow across the island to overcome local drift. Overall, it appears that the current level of genetic diversity and its distribution within the island means it is unnecessary to import unrelated genetic material to the island for management purposes. Heredity (2004) 92, 396-401, advance online publication, 10 March 2004; doi:10.1038/sj.hdy.6800433

Keywords: Jersey cattle; Island of Jersey; microsatellites; genetic diversity; inbreeding

\section{Introduction}

The characterisation of indigenous, economically important genetic resources in agriculture has become an issue of ever increasing importance, both for scientific and ownership reasons. Most countries are increasingly aware that their flora and fauna may have unique and potentially valuable genetic attributes that may be revealed through the quantification of genetic distinctiveness and/or the demonstration of genetic uniqueness. While these notions are widely recognised among conservationists for natural populations or species, the case of breeds may be even more acute, due to the large amount of artificial selection that has taken place - and which has favoured the appearance of local and economically important adaptations (Whitlock, 1980; Alderson, 1994; Hall and Bradley, 1995).

Methods to quantify the distribution of genetic diversity within and among breeds have been applied to both indigenous and ubiquitous breeds of cattle. Microsatellite data have shown that significant levels of

Correspondence: L Chikhi, UMR 5174 Evolution et Diversité Biologique, Bat. IV R3, Université Paul Sabatier, 118 Route de Narbonne, 31062 Toulouse Cédex 4, France. E-mail: chikhi@cict.fr

${ }^{5}$ The first two authors contributed equally.

Received 7 October 2002; accepted 16 January 2004; published online 10 March 2004 genetic differentiation may exist between European cattle breeds (MacHugh et al, 1994, 1998) or between herds within breeds (Blott et al, 1998b).

However, most genetic studies within cattle breeds to date have examined only limited samples within specific breeds. One exception is the study of Blott et al (1998b) who examined genetic differentiation for Hereford 'populations' from different continents.

Here, we present the first comprehensive study of the genetic structure of a cattle breed within its entire native range using the indigenous Jersey Island breed. While the Jersey has now become ubiquitous it exhibits a very significant difference with the Hereford. The Island of Jersey has been isolated from any imports of cattle from the rest of the world, including England, since 1789. We can, therefore, rule out the effects of recent introgression from other breeds as a source of genetic variation in this case. Moreover, full pedigree records have been kept for about 250 years.

We examined the genetic diversity and structure of the Jersey Island breed, comparing our estimates to those obtained for other breeds. We also examine a longstanding problem in livestock genetic diversity by addressing the effects of differing sampling regimes (across the entire island, within parishes, and farms) on estimates of genetic diversity. By doing so, we also tested for evidence of inbreeding and assessed the correlation between geographic differentiation and geographic separation among parishes. 


\section{Materials and methods}

\section{Sampling}

Cattle were sampled across the island in order to obtain individuals originating from as many parishes as possible. We obtained 223 samples from 11 out of the 12 parishes (Figure 1 in Supplementary Data), representing more than $5 \%$ of the ca 4000 cattle present on the island (Table 1). These samples also included 24 additional individuals from various additional locations on the island. This sample comprised a random mixture of cattle from the island and was used for comparisons in some of the preliminary analyses. The sample sizes varied among parishes: St John $(n=25)$, St Peter $(n=24)$, Grouville $(n=9)$, Trinity $(n=19)$, St Mary $(n=18)$, St Brelade $(n=11)$, St Saviour $(n=39)$, St Martin $(n=23)$, St Clement $(n=4)$, St Helier $(n=16)$, St Ouen $(n=11)$ (see Figure 1 in Supplementary Data and Table 1). For all parishes, except St Helier, Trinity and St Clement, cattle came from more than one farm (Table 1 in Supplementary data). Hair samples were plucked from each individual and stored in paper envelopes at room temperature.

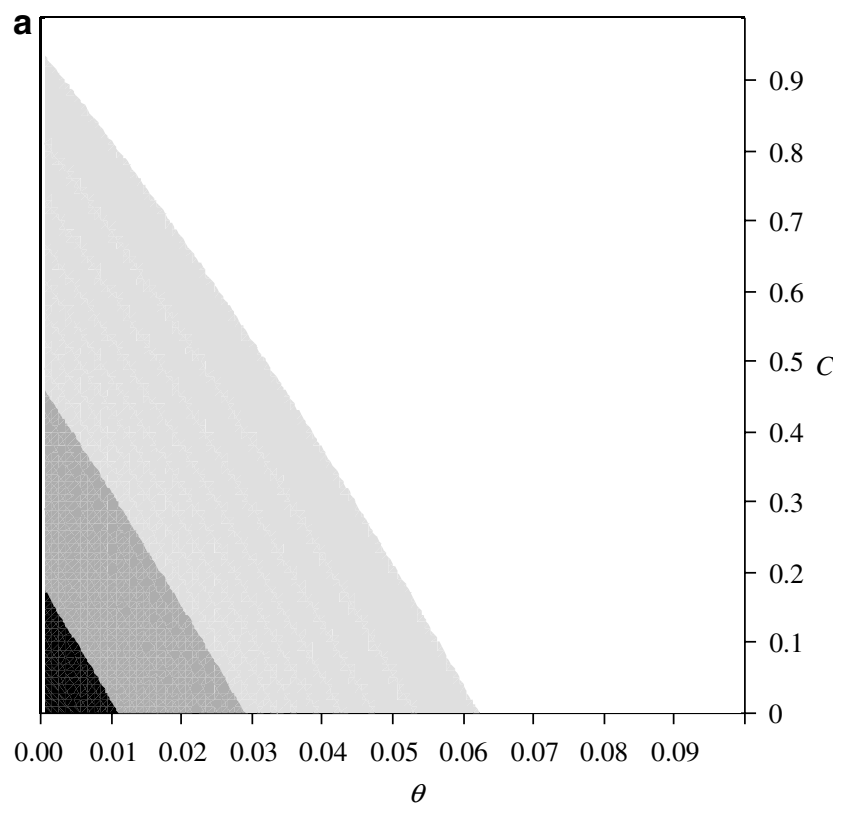

b Posterior probability for $\mathrm{K}$

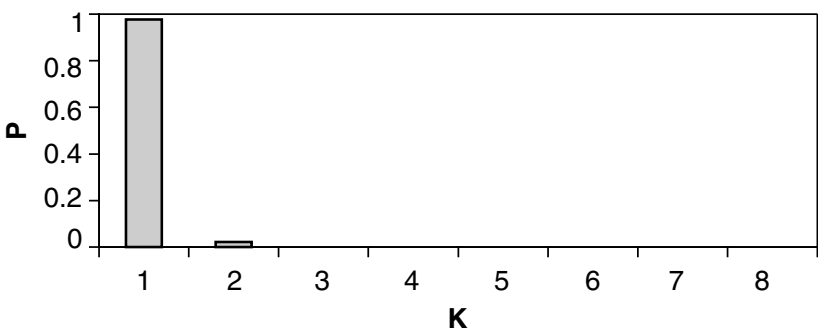

Figure 1 (a) Likelihood distribution for parameters of subdivision and consanguinity for the St Saviour parish $(n=39)$. The shaded regions correspond to 10,50 and $90 \%$ intervals of the most likely values. (b) Posterior distribution for $K$, the number of hidden partitions.
DNA extraction

DNA was extracted from at least 10 plucked hairs per individual following the Chelex-100 procedure described in Walsh et al (1991) with specific details in Goossens et al (1998). In total, $400 \mu \mathrm{l}$ samples were incubated at $56^{\circ} \mathrm{C}$ for $5-6 \mathrm{~h}$, and then put in a boiling water bath for $8 \mathrm{~min}$. In all, $2.5 \mu \mathrm{l}$ of each extract were added as template in each PCR reaction.

\section{Microsatellite analysis}

A total of 12 microsatellite loci (HAUT27, HEL5, BM1314, BM1818, BM2113, INRA005, INRA063, ILSTS006, ETH10, ETH225, TGLA122, and TGLA227 (Steffen et al, 1993; Vaiman et al, 1994; MacHugh et al, 1998)) were amplified with GibcoTaq ${ }^{\circledR}$ in a Perkin-Elmer Gene Amp PCR System 9600 . One primer from each pair was synthesized with a fluorescent dye, FAM, HEX or TET, on the $5^{\prime}$ end. Amplification of the loci was carried out in $12.5 \mu \mathrm{l}$ reactions (10 mM Tris- $\mathrm{HCl}(\mathrm{pH} 9.0), 200 \mathrm{mM}\left(\mathrm{NH}_{4}\right)_{2} \mathrm{SO}_{4}$ $50 \mu$ MeachdNTP, $1.5 \mathrm{mMMgCl}_{2}, 5$ ngBSA,0.1 UAmplitaq ${ }^{\mathbb{R}}$ Gold DNA polymerase (Perkin-Elmer), $0.5 \mu \mathrm{M}$ (for FAM) or $0.75 \mu \mathrm{M}$ (for TET) or $1 \mu \mathrm{M}$ (for HEX) fluorescent primer, same concentration for the nonfluorescent primer). Thermocycling conditions were as follows: initial denaturation at $93^{\circ} \mathrm{C}$ for $3^{\prime}$ followed by 40 cycles of $15 \mathrm{~s}$ at $95^{\circ} \mathrm{C}, 30 \mathrm{~s}$ at annealing temperatures (which varied from 50 to $60^{\circ} \mathrm{C}$ depending on the locus, see Supplementary Data of Table 2), extension of $30 \mathrm{~s}$ to $1 \mathrm{~min}$ at $72^{\circ} \mathrm{C}$ for $30^{\prime}$ to $1^{\prime}$ ), and a final extension at $72^{\circ} \mathrm{C}$ for $2^{\prime}$. All PCR products were separated on an acrylamide gel using an ABI PRISM 377 DNA sequencer. Gels were analysed using the GeneScan Analysis 2.0 ${ }^{\mathrm{TM}}$ and Genotyper $1.1^{\mathrm{TM}}$ software.

\section{Data analysis}

Genetic variability and population structure: For each parish we report the number of alleles for each locus and the mean number of alleles across loci. Single locus observed heterozygosity, $H_{\mathrm{o}}$, and unbiased expected heterozygosity, $H_{\mathrm{e}}$, were estimated according to Nei (1978) and averaged over loci following Nei (1987) (Table 1).

Wright's (1951) F-statistics $\left(\mathrm{F}_{\mathrm{it}}, \mathrm{F}_{\mathrm{is}}\right.$ and $\left.\mathrm{F}_{\mathrm{st}}\right)$ were used to analyse the distribution of genetic variability within and between breeds using Weir and Cockerham's (1984) method. Departure from Hardy-Weinberg proportions within the island and within each sample was assessed using Wright's $F_{\text {it }}$ and $F_{\text {is, }}$ respectively. The null distributions of $F_{i t}$ and $F_{i s}$ were approximated by permuting alleles within the set of samples or within each sample 1000 times, respectively. $F_{i t}$ and $F_{\text {is }}$ were then estimated for each permutation of the data. We assessed the significance level by comparing the observed value of $F_{\text {it }}$ (or $F_{\text {is }}$ ) with the distribution constructed with the permuted data.

Wright's $F_{s t}$ was measured to estimate population differentiation based on the variance of allelic frequencies among populations (estimated according to Weir and Cockerham, 1984). In order to test for departure from zero (ie no genetic differentiation), random permutations of genotypes among samples were performed. Randomisation of genotypes rather than of alleles circumvents the effect of correlation of alleles within individuals. A Mantel test was used to test for a correlation between 
Table 1 Measures of genetic diversity

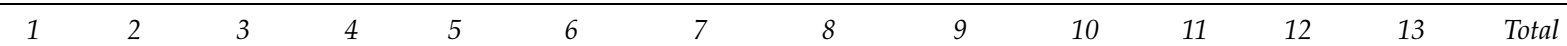

St John St Peter Grouville Trinity St Mary St Brelade St Saviour St Martin St Clement St Helier St Ouen 'moved' 'Var. Loc.'

\begin{tabular}{|c|c|c|c|c|c|c|c|c|c|c|c|c|c|c|}
\hline$n$ & 25 & 24 & 9 & 19 & 18 & 11 & 39 & 23 & 4 & 16 & 11 & 14 & 10 & 223 \\
\hline HAUT27 & 5 & 4 & 2 & 4 & 3 & 3 & 3 & 3 & 3 & 4 & 4 & 5 & 3 & 5 \\
\hline$H_{\mathrm{e}}$ & 0.6098 & 0.4087 & 0.4248 & 0.4723 & 0.4889 & 0.4502 & 0.4632 & 0.5343 & 0.6071 & 0.5786 & 0.5931 & 0.5635 & 0.4263 & 0.5028 \\
\hline$H_{\mathrm{o}}$ & 0.5200 & 0.4167 & 0.3333 & 0.5789 & 0.6111 & 0.3636 & 0.5385 & 0.3478 & 0.2500 & 0.7500 & 0.4545 & 0.6429 & 0.5000 & 0.5067 \\
\hline HEL5 & 5 & 5 & 5 & 5 & 4 & 3 & 5 & 4 & 4 & 4 & 4 & 4 & 5 & 6 \\
\hline$H_{\mathrm{e}}$ & 0.6580 & 0.5984 & 0.7582 & 0.6700 & 0.6937 & 0.3247 & 0.6863 & 0.6077 & 0.7500 & 0.7177 & 0.6623 & 0.5503 & 0.5579 & 0.6387 \\
\hline$H_{\mathrm{o}}$ & 0.5600 & 0.6250 & 0.7778 & 0.6316 & 0.8333 & 0.3636 & 0.6667 & 0.5217 & 0.7500 & 0.9375 & 0.6364 & 0.5000 & 0.7000 & 0.6457 \\
\hline BM1314 & 4 & 5 & 4 & 5 & 4 & 2 & 4 & 5 & 4 & 3 & 2 & 3 & 4 & 6 \\
\hline$H_{\mathrm{e}}$ & 0.6073 & 0.6215 & 0.5752 & 0.6302 & 0.6238 & 0.4156 & 0.5288 & 0.5720 & 0.6429 & 0.5222 & 0.5195 & 0.6111 & 0.6211 & 0.5804 \\
\hline$H_{\mathrm{o}}$ & 0.6400 & 0.4167 & 0.3333 & 0.8421 & 0.6667 & 0.5455 & 0.5897 & 0.5217 & 0.7500 & 0.6875 & 0.5455 & 0.4286 & 0.7000 & 0.5874 \\
\hline BM1818 & 5 & 4 & 4 & 5 & 5 & 5 & 6 & & 4 & 3 & 2 & 3 & 4 & 6 \\
\hline$H_{\mathrm{e}}$ & 0.5967 & 0.6144 & 0.6013 & 0.6885 & 0.7333 & 0.6147 & 0.6926 & 0.6271 & 0.4286 & 0.7802 & 0.7749 & 0.7354 & 0.7947 & 0.7156 \\
\hline$H_{\mathrm{o}}$ & 0.5200 & 0.6250 & 0.5556 & 0.6316 & 0.5556 & 0.6364 & 0.5128 & 0.6087 & 0.5000 & 0.6250 & 0.6364 & 0.5000 & 0.8000 & 0.5830 \\
\hline BM2113 & 4 & 4 & 3 & 4 & 4 & 4 & 4 & 4 & 3 & 4 & 4 & 4 & 4 & 5 \\
\hline$H_{\mathrm{e}}$ & 0.6588 & 0.6285 & 0.6601 & 0.6074 & 0.7413 & 0.6537 & 0.6750 & 0.5729 & 0.7500 & 0.7298 & 0.7229 & 0.4286 & 0.6579 & 0.6534 \\
\hline$H_{\mathrm{o}}$ & 0.7600 & 0.6250 & 0.6667 & 0.5789 & 0.7778 & 0.7273 & 0.6410 & 0.5652 & 0.7500 & 0.8125 & 0.6364 & 0.5000 & 0.5000 & 0.6547 \\
\hline INRA005 & 3 & 3 & 3 & 3 & 3 & 3 & 3 & 3 & 2 & 3 & 3 & 3 & 3 & 3 \\
\hline$H_{\mathrm{e}}$ & 0.6376 & 0.6463 & 0.5817 & 0.6529 & 0.6524 & 0.6017 & 0.6111 & 0.5807 & 0.4286 & 0.5867 & 0.6710 & 0.6376 & 0.6789 & 0.6289 \\
\hline$H_{\mathrm{o}}$ & 0.4800 & 0.6250 & 0.6667 & 0.6316 & 0.6667 & 0.7273 & 0.6410 & 0.6087 & 0.0000 & 0.8125 & 0.7273 & 0.5714 & 0.5000 & 0.6188 \\
\hline INRA063 & 3 & 3 & 3 & 3 & 3 & 3 & 3 & 4 & 3 & 3 & 4 & 3 & 3 & 5 \\
\hline$H_{\mathrm{e}}$ & 0.5641 & 0.5310 & 0.5817 & 0.5220 & 0.6238 & 0.5411 & 0.6264 & 0.6686 & 0.4643 & 0.4940 & 0.6537 & 0.3624 & 0.6368 & 0.5725 \\
\hline$H_{\mathrm{o}}$ & 0.5200 & 0.5417 & 0.3333 & 0.5789 & 0.5556 & 0.4545 & 0.5385 & 0.6087 & 0.5000 & 0.5000 & 0.6364 & 0.4286 & 0.7000 & 0.5381 \\
\hline ILSTS006 & 5 & 6 & 4 & 6 & 4 & 5 & 7 & 6 & 3 & 5 & 5 & 5 & 3 & 7 \\
\hline$H_{\mathrm{e}}$ & 0.5853 & 0.6817 & 0.7647 & 0.8151 & 0.5730 & 0.7359 & 0.7160 & 0.7304 & 0.6786 & 0.7977 & 0.6883 & 0.7302 & 0.6737 & 0.7060 \\
\hline$H_{\mathrm{o}}$ & 0.6000 & 0.7083 & 0.6667 & 0.7895 & 0.8333 & 0.6364 & 0.6410 & 0.6957 & 0.5000 & 0.6667 & 0.5455 & 0.6429 & 0.8000 & 0.6802 \\
\hline ETH10 & 5 & 5 & 5 & 4 & 4 & 4 & 5 & 5 & 4 & 4 & 4 & 5 & 4 & 5 \\
\hline$H_{\mathrm{e}}$ & 0.6049 & 0.6250 & 0.6732 & 0.7070 & 0.5762 & 0.6710 & 0.6217 & 0.5411 & 0.7857 & 0.6149 & 0.6407 & 0.5979 & 0.7263 & 0.6248 \\
\hline$H_{\mathrm{o}}$ & 0.6400 & 0.7917 & 0.7778 & 0.7368 & 0.5000 & 0.8182 & 0.6923 & 0.6522 & 0.7500 & 0.7500 & 0.4545 & 0.7143 & 0.8000 & 0.6906 \\
\hline ETH225 & 3 & 3 & 3 & 3 & 3 & 3 & 3 & 3 & 3 & 3 & 3 & 3 & 3 & 3 \\
\hline$H_{\mathrm{e}}$ & 0.6016 & 0.4406 & 0.6275 & 0.6188 & 0.6175 & 0.5541 & 0.6410 & 0.5053 & 0.7143 & 0.5988 & 0.6797 & 0.5952 & 0.4684 & 0.5988 \\
\hline$H_{\mathrm{o}}$ & 0.6400 & 0.4583 & 0.5556 & 0.6842 & 0.5556 & 0.7273 & 0.6923 & 0.3043 & 1.0000 & 0.5625 & 0.7273 & 0.8571 & 0.6000 & 0.6099 \\
\hline TGLA122 & 3 & 4 & 4 & 5 & 4 & 4 & 5 & 4 & 4 & 4 & 3 & 4 & 3 & 5 \\
\hline$H_{\mathrm{e}}$ & 0.6033 & 0.7012 & 0.7582 & 0.6913 & 0.6175 & 0.7446 & 0.6537 & 0.6531 & 0.8214 & 0.6673 & 0.6537 & 0.5212 & 0.6789 & 0.6571 \\
\hline$H_{\mathrm{o}}$ & 0.6400 & 0.7917 & 0.7778 & 0.7368 & 0.6667 & 0.7273 & 0.7179 & 0.6957 & 0.7500 & 0.7500 & 0.8182 & 0.5000 & 0.8000 & 0.7130 \\
\hline TGLA227 & 8 & 8 & 6 & 8 & 7 & 7 & 8 & 8 & 6 & 9 & 5 & 8 & 6 & 11 \\
\hline$H_{\mathrm{e}}$ & 0.8253 & 0.8209 & 0.8497 & 0.8535 & 0.7905 & 0.7965 & 0.7692 & 0.8164 & 0.9286 & 0.8831 & 0.6277 & 0.8783 & 0.6211 & 0.8371 \\
\hline $\begin{array}{l}H_{\mathrm{o}} \\
\text { Total }\end{array}$ & 0.9200 & 0.8333 & 0.6667 & 0.9474 & 0.8889 & 0.7273 & 0.7692 & 0.6522 & 1.0000 & 0.7500 & 0.6364 & 0.9286 & 0.6000 & 0.7982 \\
\hline$n_{\mathrm{A}}$ & 4.42 & 4.50 & 3.83 & 4.58 & 4.00 & 3.83 & 4.67 & 4.42 & 3.42 & 4.25 & 3.75 & 4.42 & 4.00 & \\
\hline$H_{\mathrm{e}}$ & 0.6294 & 0.6099 & 0.6547 & 0.6607 & 0.6443 & 0.5920 & 0.6404 & 0.6175 & 0.6667 & 0.6643 & 0.6573 & 0.6010 & 0.6285 & 0.6430 \\
\hline$H_{\mathrm{o}}$ & 0.6200 & 0.6215 & 0.5926 & 0.6974 & 0.6759 & 0.6212 & 0.6368 & 0.5652 & 0.6250 & 0.7170 & 0.6212 & 0.6012 & 0.6667 & 0.6355 \\
\hline
\end{tabular}

$n$ is the sample size, $H_{\mathrm{o}}$ and $H_{\mathrm{e}}$ are the observed and expected heterozygosities, and $n_{\mathrm{A}}$ is the mean number of alleles.

Table 2 Pairwise $\mathrm{F}_{\mathrm{st}}$ values between parishes

\begin{tabular}{lcccccccccccccc}
\hline & St John & St Peter & Grouville & Trinity & St Mary & St Brelade & St Saviour & St Martin & St Clement & St Helier & St Ouen 'moved' 'Var. loc.' \\
\hline St John & 0 & 0.00989 & -0.00074 & $\mathbf{0 . 0 3 2 9 8}$ & 0.00309 & $\mathbf{0 . 0 2 0 2 4}$ & 0.00561 & 0.00110 & 0.03242 & $\mathbf{0 . 0 2 2 8 1}$ & 0.00774 & 0.01245 & $\mathbf{0 . 0 2 5 3 5}$ \\
St Peter & NS & 0 & & -0.00336 & $\mathbf{0 . 0 3 4 4 3}$ & 0.00965 & 0.01059 & $\mathbf{0 . 0 1 4 5 5}$ & 0.00531 & 0.03118 & $\mathbf{0 . 0 3 1 1 2}$ & 0.01561 & $\mathbf{0 . 0 2 4 2 8}$ & $\mathbf{0 . 0 2 5 0 2}$ \\
Grouville & NS & NS & 0 & $\mathbf{0 . 0 2 3 9 3}$ & 0.00194 & 0.00785 & -0.00496 & -0.00371 & -0.00894 & -0.00179 & 0.00665 & 0.01516 & $\mathbf{0 . 0 3 1 8 8}$ \\
Trinity & $* * *$ & $* * *$ & $*$ & 0 & & $\mathbf{0 . 0 3 1 7 6}$ & $\mathbf{0 . 0 5 1 9 0}$ & $\mathbf{0 . 0 2 9 1 2}$ & $\mathbf{0 . 0 3 4 5 8}$ & 0.05077 & 0.01234 & 0.01273 & 0.01116 & $\mathbf{0 . 0 2 7 6 7}$ \\
St Mary & NS & NS & NS & $* * *$ & 0 & & $\mathbf{0 . 0 3 7 6 7}$ & 0.00909 & 0.01252 & $\mathbf{0 . 0 1 4 9 2}$ & 0.01178 & 0.00293 & $\mathbf{0 . 0 2 7 0 0}$ & 0.01733 \\
St Brelade & $*$ & NS & NS & $* *$ & $* *$ & 0 & & 0.01156 & 0.00911 & 0.01360 & $\mathbf{0 . 0 3 7 9 2}$ & 0.01656 & $\mathbf{0 . 0 3 6 2 2}$ & $\mathbf{0 . 0 3 0 1 3}$ \\
St Saviour & NS & $* *$ & NS & $* * *$ & NS & NS & 0 & 0.00151 & 0.02188 & 0.00945 & 0.00621 & $\mathbf{0 . 0 2 0 0 0}$ & $\mathbf{0 . 0 1 7 4 9}$ \\
St Martin & NS & NS & NS & $* * *$ & NS & NS & NS & 0 & 0.04078 & $\mathbf{0 . 0 2 1 0 4}$ & 0.00237 & 0.01354 & $\mathbf{0 . 0 2 7 7 0}$ \\
St Clement & NS & NS & NS & $*$ & NS & NS & NS & NS & 0 & & 0.02175 & 0.02027 & $\mathbf{0 . 0 5 7 8 3}$ & $\mathbf{0 . 0 7 1 7 6}$ \\
St Helier & $* *$ & $* *$ & NS & NS & NS & $* *$ & NS & $*$ & NS & 0 & 0.01774 & $\mathbf{0 . 0 2 4 3 3}$ & 0.02153 \\
St Ouen & NS & NS & NS & NS & NS & NS & NS & NS & NS & NS & 0 & 0.01015 & 0.02016 \\
'Moved' & NS & $*$ & NS & NS & $*$ & $*$ & $*$ & NS & $*$ & $*$ & NS & 0 \\
'Var. Loc.' & $*$ & $*$ & $*$ & $*$ & NS & $*$ & $*$ & $*$ & $* *$ & NS & NS & $*$ & 0.04471 \\
\hline
\end{tabular}

Significant values are in bold. NS, not significant; ${ }^{* *} P<0.001 ;{ }^{* *} 0.001 \leqslant P<0.01 ;{ }^{*} 0.01 \leqslant P<0.05$.

genetic and geographic distances between parishes or farms.

All these computations were performed using GENETIX 4.0 (available at http: / / www.univ-montp2.fr / genetix / genetix.htm).
We also used a recent method developed by Overall and Nichols (2001) to separate the effect of substructure (Wahlund effect) and consanguinity in apparent inbreeding as measured by positive $F_{\text {is }}$. The method generates the joint likelihood distribution of $\theta$ (Weir and 
Cockerham's measure of $\mathrm{F}_{\mathrm{st}}$ ) and $\mathrm{C}$, the proportion of the population that is consanguineous to a certain level and therefore allows us to find the maximum likelihood values for both parameters. The proportion $\mathrm{C}$ depends on how consanguineous individuals are, and the calculation can be done including many different levels of consanguinity at once. However, given the low levels of inbreeding observed, the analysis was carried out for a value of $1 / 16$ corresponding to offspring of first cousins (A Overall, pers. comm.).

Dawson and Belkhir (2001) recently developed a method that detects and tests for partition within any genetic sample without prior information on the origin of individuals. This method allows the detection of up to 12 partitions (or subgroups). A Monte Carlo Markov Chain (MCMC) approach using the Metropolis-Hastings algorithm is taken to explore the parameter space defined by (i) $K$, the number of possible partitions, and (ii) the distribution of individuals in the $K$ partitions. During this process the likelihood of the data is estimated for the different $K$ values and possible assignments of individuals to the $K$ partitions. The theory shows that when the chain reaches equilibrium the different values of $K$ have been sampled in proportion to their probability of generating the data. It therefore becomes possible to estimate the posterior probability distribution of $K$ and jointly estimate the posterior probability that any two individuals belong to the same partition. A value of $K=1$ thus means that no hidden substructure is detected in the data set. The advantage of this method is that it does not depend on the units defined by our sampling strategy. It tries to recover any hidden partition in the data. The maximum value of $K$ has to be specified beforehand. Given that the time of the analysis increases very quickly with increasing $K$ values, the maximum was set to $K=8$ and proved to be large enough.

\section{Results and discussion}

\section{Variability and isolation}

In total, 67 alleles were detected at the 12 loci surveyed among the 223 Jersey cattle, giving a mean number of approximately four alleles per locus (Table 1). This number varied across loci with only three alleles at INRA005 and ETH225 and 11 alleles at TGLA227. The average number of alleles per sample per locus exhibited some variation with 3.42 alleles in St Clement (which was the smallest sample with only four cattle) and 4.67 in St Saviour. $H_{\mathrm{e}}$ values varied between 0.32 in St Brelade (locus HEL5) and 0.93 in St Clement (locus TGLA227). The average $H_{\mathrm{e}}$ values for each sample varied between 0.59 in St Brelade and 0.67 in St Clement, with a global average of 0.64 .

A previous genetic study found that the Jersey cattle seemed to exhibit a reduced genetic diversity when compared to continental breeds (MacHugh et al, 1994). These authors found that, using 12 microsatellites, the British Isles breeds only had 3.3 alleles per locus compared to 4.3 in a number of continental breeds such as the Charolais, Friesian and Simmental. A later study based on 20 loci (MacHugh et al, 1998) confirmed the high level of genetic diversity of the Charolais and Friesian breeds.
While these results seem to conform to the expectation that island breeds will have lower effective sizes and therefore exhibit lower $H_{\mathrm{e}}$ values, there are two important caveats in such comparisons. First, the large genetic diversity observed in Charolais and Friesian breeds appears to be explained by the introgression of genes from a number of smaller breeds (MacHugh et al, 1997). In other words, admixture events taking place in some herds, whether known or unrecorded, may bias $H_{\mathrm{e}}$ estimations. Second, the loci used appear to also influence the apparent level of diversity. This effect, which is related to ascertainment bias, is rarely acknowledged, probably because it is difficult to assess, but appears to be substantial in the study of MacHugh et al (1994). Indeed all breeds, including the Jersey cattle, had a $H_{\mathrm{e}}$ between 0.403 and 0.488 whereas more recent studies (Peelman et al, 1998; Loftus et al, 1999; Martin-Burriel et al, 1999, Table 3) found $H_{\mathrm{e}}$ values mostly between 0.55 and 0.70 . In fact, MacHugh et al's (1994) study was among the first and used microsatellites linked to genes without prior polymorphism pre-screening.

Assuming that, with the exception of the MacHugh et al (1994) study, $H_{\mathrm{e}}$ values can be compared across published data, Jersey cattle appear to be just as variable as a number of continental breeds (Table 3). This assumption can be tested by recalculating $H_{\mathrm{e}}$ values for the seven loci that are in common between our study and that of Loftus et al (1999), for which we find $H_{\mathrm{e}}=0.63$ (the value found by these authors).

Our results thus indicate that (i) despite its isolation and particular history the Island Jersey is far from being the least variable of cattle breeds, (ii) more work is needed on the distribution of variability across loci.

\section{Inbreeding and isolation}

Overall, the average $F_{i t}$ across loci was positive and highly significant $\left(\mathrm{F}_{\mathrm{it}}=0.013, P<0.001\right)$. While this might be interpreted as significant inbreeding at the island level we are able to show that a Wahlund effect is the most likely explanation. For instance, most $F_{\text {is }}$ values were low within parishes and nonsignificant (overall $\mathrm{F}_{\text {is }}=-0.003$, NS). The 11 significant $F_{\text {is }}$ values did not show any local trend (see Supplementary Data of Table 2). The only parish that exhibited an overall significant $\mathrm{F}_{\text {is }}\left(\mathrm{F}_{\text {is }}=0.086\right.$, $P<0.05)$ was St Martin but the method of Overall and Nichols (2001) indicated that it was most likely due to substructure. At the farm level, average $F_{\text {is }}$ values were negative but not significant $\left(\mathrm{F}_{\mathrm{is}}=-0.023, \mathrm{NS}\right)$.

These results were confirmed by the Overall and Nichols (2001) method, which showed no apparent departure from random mating for most parishes. The maximum likelihood was zero for both parameters, as exhibited in Figure 1a for St Saviour. When all samples were analysed together there appeared to be a slight level of inbreeding. However, when we conditioned on the observed $\mathrm{F}_{\mathrm{st}} \sim 0.01$ (see below), this effect disappeared.

Allan (1987) showed, based on pedigree analysis, that the level of inbreeding observed in Island Jersey was relatively low (around 0.06) and he concluded that it was not potentially damaging to the breed. Our conclusions (based on the ability to separate the effect of inbreeding and substructure) confirm that there is no genetic threat 
Table 3 Levels of variability among European cattle breeds in recent microsatellite studies

\begin{tabular}{|c|c|c|}
\hline $\begin{array}{l}\mathrm{Nb} \\
\text { loci }\end{array}$ & Breeds $\left(H_{e}\right)$ & Ref. \\
\hline 23 & $\begin{array}{l}\text { Belgian Blue }(0.65), \text { Holstein Friesian } \\
(0.69), \text { East Flemish }(0.69), \text { Red Pied } \\
(0.71)\end{array}$ & $\begin{array}{l}\text { Peelman et al } \\
\text { (1998) }\end{array}$ \\
\hline 30 & $\begin{array}{l}\text { Menorquina (0.564), Fighting Bull } \\
(0.590) \text {, Pyrenean }(0.617) \text {, Asturian } \\
\text { Mountain }(0.667) \text {, Nordwest Brown } \\
\text { group }(0.671) \text {, Asturian Lowland }(0.681)\end{array}$ & $\begin{array}{l}\text { Martin-Burriel } \\
\text { et al (1999) }\end{array}$ \\
\hline 20 & No $\mathrm{H}_{\mathrm{e}}$ values given. & $\begin{array}{l}\text { MacHugh et al } \\
\text { (1998) }\end{array}$ \\
\hline 12 & $\begin{array}{l}\text { Hereford }(0.403), \text { Jersey }(0.410) \text {, Angus } \\
(0.415) \text {, Simmental }(0.432) \text {, Charolais } \\
(0.46) \text {, Friesian }(0.488)\end{array}$ & $\begin{array}{l}\text { MacHugh et al } \\
\text { (1994) }\end{array}$ \\
\hline 20 & $\begin{array}{l}\text { N'Dama (0.54), Hungarian Grey (0.62), } \\
\text { Jersey (0.63), Ongole (0.64), Nellore } \\
(0.65) \text {, Charolais (0.66), Damascus }(0.74) \text {, } \\
\text { Turkish Grey (0.76), Anatolian Black } \\
\text { (0.78), South Anatolian Red (0.78), East } \\
\text { Anatolian Red (0.78), Egypt (0.78), Iraqi } \\
(0.78), \text { Kurdi (0.79) }\end{array}$ & $\begin{array}{l}\text { Loftus et al } \\
\text { (1999) }\end{array}$ \\
\hline 12 & Jersey $(0.64)$ & This study \\
\hline
\end{tabular}

currently posed by keeping the island demographically isolated. Importation of semen from American and Australian Jersey cattle to increase the gene pool for selection on the island and allow genetic improvement in the breed has been suggested. However, in the absence of molecular evidence for a genetically depauperate island population there seems little scientific reason to ignore Allan's recommendations.

\section{Differentiation between parishes and farms}

The average $F_{\text {st }}$ value was low but highly significant between parishes $\left(\mathrm{F}_{\mathrm{st}}=0.016, P<0.001\right)$ explaining most of the overall $F_{i t}$. The pairwise $F_{s t}$ values ranged from -0.009 (ie 0 ) to 0.070 (Table 2). Removing the 'moved' and 'Various locations' samples, together with the St Clement sample, only resulted in minimal change $\left(F_{\text {st }}=0.013\right.$, $P<0.001)$. As expected, the genetic differentiation between farms was higher than between parishes and is also highly significant $\left(\mathrm{F}_{\mathrm{st}}=0.035, P<0.001\right)$. The partition analysis revealed a similar pattern. The posterior distribution for $K$, the number of partitions within the whole island, is shown in Figure 1b. It clearly indicates a high support for the whole island being considered as one (more or less) panmictic population with only ca $2 \%$ support for a bipartition, and no support for $K>2$. The result of the Mantel test was not significant $(r=-0.036$, NS), indicating no significant correlation between geographic and genetic distances.

The existence of significant genetic differentiation is not surprising. The surprising result was the low $\mathrm{F}_{\mathrm{st}}$ value. With a total population size of around 4000, cattle there are on average less than 400 cattle per parish. Assuming that drift occurred between parishes in the last 250 years (with approximately 5 years per generation), $\mathrm{F}_{\mathrm{st}}$ could have increased up to 0.06 (assuming that the effective size $N_{\mathrm{e}}=N$ ). Given that $N_{\mathrm{e}}$ is likely to be considerably lower than the population size, we find that, if $N_{\mathrm{e}}=N / 3, \mathrm{~F}_{\mathrm{st}}=0.15$, a value commonly found between breeds. Indeed, breed demographic histories are complex and can generate high levels of genetic differentiation. In sheep we found $F_{\text {st }}$ values as high as 0.09 between flocks of some European breeds, with a maximum of 0.12 between Soay flocks (Byrne et al, in press). Similarly, Blott et al (1998a) have found that levels of differentiation between recently separated Hereford cattle overlapped with those observed between the Hereford and other European breeds.

The observed $\mathrm{F}_{\mathrm{st}}$ values are thus much lower than expected under pure drift and would have been reached in less than 50 and 20 years with $N_{\mathrm{e}}=N$ and $N_{\mathrm{e}}=N / 3$, respectively. Thus, our results strongly suggest that gene flow across the island may be more widespread than we first hypothesised. This conclusion, was, as we saw, confirmed by the partition analysis. A mean $\mathrm{F}_{\mathrm{st}}$ between parishes smaller than 0.02 indicates that, on average, each parish still retains more than $98 \%$ of the variability present on the whole island. At the farm level, the average is around $97 \%$. While more similar work would be needed to assess within-breed differentiation in continental breeds, these results suggest that sampling only some areas of the island is likely to provide a good sample of the total genetic diversity of the Island Jersey.

\section{Conclusion}

Jersey Island cattle are unique in having been purposefully isolated from other UK and mainland European cattle populations for approximately 50 generations. For much of this period of isolation cattle are thought to have been mostly managed in relatively small groups on farms, mainly breeding with individuals located within a short distance (for example, on farms within the same parish). This kind of demographic history was expected to have generated (i) reduced diversity compared to breeds from the continent or mainland UK (eg Frankham, 1997), (ii) medium to high $F_{\text {st }}$ values perhaps associated with (iii) some isolation by distance. While the extent of such effects was not easy to predict a priori, our results suggest that none is clearly detectable. Despite the increasing worries of farmers that inbreeding was accumulating across the island, our results suggest that the Jersey Island cattle is just as variable as many other breeds. The level of inbreeding is low and does not appear to justify imports of semen from other Jersey populations.

While imports could indeed bring new alleles or genotypes, it is far from clear whether it is really necessary. Our recommendation of keeping the island isolated also draws from the experience of the Hereford cattle, another ubiquitous breed with huge success outside its area of origin. Blott et al (1998b) have shown that, for this British breed, imports from Canadian populations with higher performance have negatively affected the genetic diversity of the Hereford in the British Isles. The reason for this is that as soon as imports are possible, the risk exists that farmers will tend to import semen offered from the same sires, potentially reducing the gene pool for future generations.

However, breeds can potentially suffer similar demographic and genetic problems to threatened species and other small populations: genetic drift can arise rapidly under conditions of intense selection and artificial insemination. 
The level of genetic diversity observed in a breed is the result of a number of complex demographic factors and current or recent population size is not the only one of these. Indeed, the Hereford, Jersey and Holstein Friesian are all ubiquitous breeds but appear to exhibit different levels of polymorphism (Table 3). Similarly, the Belgian Blue has the largest population size of four Belgian breeds studied (Peelman et al, 1998), yet it had the lowest $H_{\mathrm{e}}$ value. This was explained by the fact that the Belgian Blue is a closed population whereas the other Belgian breeds had been graded up, resulting in the incorporation of new alleles and an increase in genetic variability. One recommendation would also be that cattle such as the Jersey could serve as interesting comparisons with threatened species. The conservation genetics literature rarely uses information from such breeds and we hope that the present study might provide important comparative data. Just as it is true for a number of protected species, the future genetic status of the Jersey Island cattle remains reliant on careful management.

\section{Acknowledgements}

LC was supported by MAFF contract OC9316B to MWB, the Institute of Zoology and Cardiff University. BG was supported by Leverhulme Grant F/390/U to MWB and JR de Ruiter and by DETR Darwin Initiative grant 09/016 to MWB. We thank Kate Byrne, Saffron Townsend, Rob Cuickshank and Jan de Ruiter for laboratory and sampling assistance and collaboration on MAFF contracts OCS9316 and OC9316B. Thanks also go to Dr GLH Alderson (Rare Breeds International), the Rare Breeds Survival Trust, Drs. Emma Hennessey and John Caygill (Chief Scientist's Group, MAFF), Dr Jean-Pierre Garnier (Meat Trade Advisor, MAFF) and Elizabeth Henson (Liaison Officer, MAFF) for their support throughout this project. We are very grateful to Andy Overall for the inbreeding analysis and for comments on the results and especially to James Godfrey and David Hambrook (Jersey Society) and all the farmers from Jersey who allowed us to sample in their farms. This project is part of a programme in MWB's laboratory on genetic resource management in livestock, funded by DEFRA and the EC (www.cf.ac.uk/biosi/research/biodiversity/ staff $/ \mathrm{mb}$.html). Data are available upon request from the corresponding author.

\section{References}

Alderson L (1994). The Chance to Survive. Pilkington Press: Yelvertoft.

Allan J (1987). To import the semen of superior tested sires or not to import semen. The Albert Messervy Memorial Conference.

Blott SC, Williams JL, Haley CS (1998a). Genetic relationships among European cattle breeds. Anim Genet 29: 273-282.
Blott SC, Williams JL, Haley CS (1998b). Genetic variation within the Hereford breed of cattle. Anim Genet 29: 202-211.

Byrne K, Chikhi L, Townsend SJ, Cruikshank R, Alderson L, Bruford MW. Genetic diversity in phenotypically diverse European sheep breeds: rarity and conservation. Mol Ecol (in press).

Dawson KJ, Belkhir K (2001). A Bayesian approach to the identification of panmictic populations and the assignment of individuals. Genet Res 78: 59-77.

Frankham R (1997). Do island populations have less genetic variation than mainland populations? Heredity 78: 311-327.

Goossens B, Waits LP, Taberlet P (1998). Plucked hair samples as a source of DNA: reliability of dinucleotide microsatellite genotyping. Mol Ecol 7: 1237-1241.

Hall SJG, Bradley DG (1995). Conserving livestock breed biodiversity. Trends Ecol Evol 10: 267-270.

Loftus RT, Ertugrul O, Harba AH, El Barody MA, MacHugh DE, Park SD, Bradley DG (1999). A microsatellite survey of cattle from a centre of origin: the Near East. Mol Ecol 8: 20152022.

MacHugh DE, Loftus RT, Bradley DG, Sharp PM, Cunningham $P$ (1994). Microsatellite DNA variation within and among European cattle breeds. Proc Roy Soc London B Biol Sci 256: 25-31.

MacHugh DE, Loftus RT, Cunningham P, Bradley DG (1998). Genetic structure of seven European cattle breeds assessed using 20 microsatellite markers. Anim Genet 29: 333-340.

MacHugh DE, Shriver MD, Loftus RT, Cunningham P, Bradley DG (1997). Microsatellite DNA variation and the evolution, domestication and phylogeography of taurine and zebu cattle (Bos taurus and Bos indicus). Genetics 146: 1071-1086.

Martin-Burriel I, Garcia-Muro E, Zaragoza P (1999). Genetic diversity analysis of six Spanish native cattle breeds using microsatellites. Anim Genet 30: 177-182.

Nei M (1978). Estimation of heterozygosity and genetic distance from a small number of individuals. Genetics 89: 583-590.

Nei M (1987). Molecular Evolutionary Genetics. Columbia University Press: New York.

Overall AD, Nichols RA (2001). A method for distinguishing consanguinity and population substructure using multilocus genotype data. Mol Biol Evol 18: 2048-2056.

Peelman LJ, Mortiaux F, Van Zeveren A, Dansercoer A, Mommens G, Coopman F et al (1998). Evaluation of the genetic variability of 23 bovine microsatellite markers in four Belgian cattle breeds. Anim Genet 29: 161-167.

Steffen P, Eggen A, Dietz AB, Womack JE, Stranzinger G, Fries R (1993). Isolation and mapping of polymorphic microsatellites in cattle. Anim Genet 24: 121-124.

Vaiman D, Mercier D, Moazami-Goudarzi K, Eggen A Ciampolini R, Lepingle A et al (1994). A set of 99 cattle microsatellites: characterization, synteny mapping, and polymorphism. Mamm Genome 5: 288-297.

Walsh PS, Metzger DA, Higuchi R (1991). Chelex 100 as a medium for simple extraction of DNA for PCR-based typing from forensic material. Biotechniques 10: 506-513.

Weir BS, Cockerham CC (1984). Estimating F statistics for the analysis of population structure. Evolution 38: 1358-1370.

Whitlock R (1980). Rare Breeds the Vulnerable Survivors. Prism Press: Chalmington, Dorchester.

Wright S (1951). The genetical structure of populations. Ann Eugenics 15: 323-354.

Supplementary Information accompanies the paper on Heredity website ( http://www.nature.com/hdy). 